\title{
Environmental context and recognition memory reconsidered
}

\author{
STEVEN M. SMITH \\ Texas A\&M University, College Station, Texas
}

\begin{abstract}
This study demonstrated that environmental-context(EC)-dependent memory can occur with recognition memory. In Experiment 1, five lists were presented, each in a different room, and recognition memory for all five lists was tested in one of the five rooms. On a yes-no recognition test, recognition was reliably affected by EC. In Experiment 2, two lists were studied, each in a different room, and memory for both lists was tested in one of the two rooms, using either freerecall, cued-recall, or recognition testing. Reliable effects of the test room were found only on the recognition test, which contained a randomized mix of the two lists. The results of both experiments show that contrary to the prevailing belief, EC-dependent recognition does occur in the laboratory.
\end{abstract}

It has often been found that event memory is improved if the background environmental context (EC) of the event is reinstated (e.g., Godden \& Baddeley, 1975; Smith, 1979; Smith, Glenberg, \& Bjork, 1978). This phenomenon is sometimes referred to as context-dependent memory (CDM). A number of studies, however, have failed to find environmental CDM when recognition, rather than recall, was tested (Godden \& Baddeley, 1980; Jacoby, 1983; Smith et al., 1978). For example, in an unpublished pilot study conducted in our laboratories, memory of list words was tested in the same context (SC) as that in which original learning had occurred, or else in a different context (DC), first with a free-recall test and then with a recognition test. That study found a robust effect of the test context for free-recall scores $[\mathrm{F}(1,56)=11.57, \mathrm{p}<.01]$, with $\mathrm{SC}$ subjects recalling $22 \%$ more than DC subjects; yet, when recognition of the same list was tested for the same subjects, performance (d') was nearly identical for SC and DC groups $[F(1,56)=0.00]$.

Investigations of state-dependent memory (SDM), a phenomenon analogous to CDM, have also generally failed to detect the effects of variations of the background context (defined as internal drug or mood state) when recognition memory was tested (Bartlett \& Santrock, 1979; Eich, 1980; Spear, 1978). Eich (1980), for example, in an archival study, showed that of 26 studies of SDM that used free-recall testing, $23(88 \%)$ found evidence of SDM, whereas of the 13 SDM studies that used recognition tests, only two (18\%) showed evidence of SDM.

\footnotetext{
Thanks are especially due Art Glenberg, who contributed a great deal to this research. Thanks are also due Kelvin Carrington, who collected the data for Experiment 1, and Steven Blankenship and Cynthia Higgs, who collected the data for Experiment 2. Requests for reprints should be sent to Steven M. Smith, Department of Psychology, Texas A\&M University, College Station, Texas 77843 .
}

In the present study, EC-dependent recognition memory was further tested by using a within-subjects comparison of SC versus DC conditions. If EC manipulations do have small effects upon recognition memory, then the reduced error variance incurred with the within-subjects comparison may help such effects show up in the data.

\section{EXPERIMENT 1}

Subjects in Experiment 1 studied five lists of words each in a different room. The recognition memory test, which tested words from all five lists, was arranged in either blocked or randomized orders. On the blocked test, words were grouped according to their input list, thus preserving some of the original structural components on the test. The randomized test, on the other hand, mixed together words from all five input lists.

\section{Method}

Subjects. Forty student volunteers from the introductory psychology class at the University of Wisconsin received course credit for participating in the 1-h experiment.

Procedure. Five 20-word lists were presented to subjects via audiotape. Words were spoken by a male voice at 3-sec intervals. The subjects were instructed to memorize words to the best of their ability. List 1 was presented in Room A, List 2 in Room B, List 3 in Room C, List 4 in Room D, and List 5 in Room E. After List 5, the subjects were taken to their recognition test room (if the test room was Room E, the subjects moved into the hall momentarily before returning to Room E).

For the recognition test, the subjects were given a test booklet containing 20 pages, with 10 words printed on each page. They were given $30 \mathrm{sec}$ per page to circle words from the five word lists. The list words were mixed in with an equal number of distractors.

Materials. Two hundred high-frequency one-syllable four- and five-letter English nouns were selected from the Kücera and Francis (1967) word frequency norms. These were divided randomly into two sets of 100 words, Set $X$ and Set $Y$. Each set was then divided randomly into five 20 -word lists. The word lists were recorded on audiocassette tape by a male voice.

All 200 words appeared on the recognition test. The test words were typed onto the pages of a 20 -page booklet ( 10 words per page). 
Each page contained a mix of five Set $\mathrm{X}$ words and five Set $\mathrm{Y}$ words. Since the subjects heard only one set of words, the other set always served as distractors.

The recognition tests were either blocked or randomized. The pages of the randomized test each contained one old word from each of the five lists, plus five distractors. On the blocked test, all old words on a page were from the same list (but not in their original order); the first four pages contained List 1 words with distractors, the next four had List 2 words, and so forth, for Lists 3, 4 , and 5 , in that order.

Design. The three between-subjects factors were test type (blocked or randomized), test room (Room A, B, C, D, or E), and word set (Set $\mathrm{X}$ or Set $\mathrm{Y}$ ). For each subject, recognition memory performance for the list associated with the test room (SC list) was compared with performance on the other four lists (DC lists).

Environmental contexts. Room A was a fairly empty room on the second floor of the Brogden Psychology Building: It contained only desk chairs, a slide projector, a viewing screen, a wastebasket, and a cabinet. Room B was a large room in the basement of the building. There was a large orange drapery hanging from the ceiling, a sink, books, a table, and chairs. Room $\mathrm{C}$ was on the fifth floor of the psychology building near the animal laboratories. The subjects sat in a crowded soundproof booth inside a room filled with computer equipment. Room D was a cramped and cluttered room on the fourth floor of the psychology building. The subjects were seated at two small tables in a room otherwise crammed with books, papers, and tape-recording equipment. Room E was a small uncluttered room on the fourth floor of the psychology building. In addition to the table at which the subjects sat, the room contained a soundproof booth, cabinets, and miscellaneous electronic lab equipment.

\section{Results and Discussion}

An $A^{\prime}$ score for each subject and each list was calculated. ${ }^{1}$ Each separate list had its own false-alarm rate in the blocked test condition, since lists were separated on that recognition test. In the randomized test condition, however, one pooled false-alarm rate was used for all five lists, since lists were mixed together on the randomized test.

For each subject, a context score was determined by subtracting the mean $\mathrm{A}^{\prime}$ for $\mathrm{DC}$ lists from the $\mathrm{A}^{\prime}$ score on the SC list. Positive context scores indicate an advantage for SC testing. A $2 \times 5=$ [test type (random vs. blocked) $\times$ test room (Room A, B, C, D, or E)] ANOVA was computed using context score as the dependent measure. Overall, context scores (Table 1) were significantly greater than zero $[\mathrm{t}(30)=2.12, \mathrm{MSe}=.0033, \mathrm{p}<.05]$. The mean context score, .02, was small, but reliably greater than zero. This is the first reported finding of ECdependent recognition memory.

Context scores were not affected by the type of test $[F(1,30)=.21, p=.65]$. The mean context score for

Table 1

Experiment 1: Mean Recognition Performance ( $A^{\prime}$ ) for SC and DC Lists on Blocked and Randomized Tests

\begin{tabular}{lcc}
\hline & \multicolumn{2}{c}{ Type of Test } \\
\cline { 2 - 3 } & Blocked & Random \\
\hline Same Context (SC) & .817 & .912 \\
Different Context (DC) & .794 & .897 \\
Context Score (SC - DC) & .023 & .015 \\
\hline
\end{tabular}

the blocked test condition (.023) was slightly larger than that for the randomized test condition (.015).

Although the blocked condition produced a slightly larger EC effect, its error variance was eight times that of the randomized condition. The conservative conclusion is that although EC-dependent recognition was reliably observed, the influence of test type upon this EC effect is not clear at this time.

\section{EXPERIMENT 2}

Experiment 2 also used a within-subjects manipulation to examine CDM in free-recall, cued-recall, and recognition memory tests. It was predicted that contextual cuing would be strongest for a free-recall test, which provides only general context cues. Cued recall was predicted to be less affected by the test context, and recognition was predicted to be least affected of all, since highly specific cues are provided by the test.

All subjects in Experiment 2 were given a single study and test trial for each of two lists of word pairs. Each list was presented in a different room. A test covering both word lists was given in one of the two rooms. The order of the test items was randomized on the cued-recall and recognition tests.

Experiment 2 also examined field dependence and its interaction with CDM. Field independence is a broadly defined personality trait, often measured by a rod-andframe test or by an embedded figures test (e.g., Oltman, Raskin, \& Witkin, 1971). Smith and Rothkopf (1984) found that multiple learning environments enhance memory performance for field-dependent subjects but not for field-independent ones. Field-independent subjects, however, are better able to use an instruction to recall their learning environment to facilitate memory for learned material (Smith, 1983). It seems possible that the cognitive style (i.e., field dependence) that makes individuals unable to disembed a figure from its perceptual context may also make them more aware of the background context of learned material. It was predicted that field-dependent subjects would be more affected by the test room than would field-independent subjects.

\section{Method}

Subjects. Students in the introductory psychology classes at Texas A\&M University were given the Group Embedded Figures Test (GEFT) developed by Oltman et al. (1971). Pretested subjects who scored 13 and above were called high scorers, or field independent, whereas those scoring below 13 were low scorers, or field dependent. Separate recruitment lists were used to recruit 120 fielddependent and 120 field-independent subjects. The subjects participated in groups ranging from four to six at a time. Whenever such a balance was possible, half of the subjects in each group were field dependent, and half were field independent.

Design and Procedure. The subjects were given two lists of paired associates and a final memory test covering both lists of words. List 1 was presented in Room A, and List 2 in Room B. The final test, either free recall, cued recall, or recognition, was given either in Room A or in Room B. Half of the subjects learned word Set X, and half learned Set Y. Thus, the variables examined were GEFT (field independent vs. field dependent), test room (Room 
A or B), test type (free recall, cued recall, recognition), and word set (set X or Set $Y$ ) as between-subjects factors. The dependent variable was the number correct on the SC list minus the number correct on the DC list.

The lists were presented via audiocassette tape by a male voice. Word pairs were spoken at 5-sec intervals. Immediately after one presentation of a list, a page with a list of stimulus words was given out, and the subjects were instructed to write down as many response words as possible. The subjects moved briefly to the hall after each list had been presented and tested.

The final test, given in Room A or B, was either free recall, cued recall, or recognition. For the free-recall test, the subjects were given a blank piece of paper and asked to write, for $5 \mathrm{~min}$, in any order, the words they could remember from both lists, including both stimulus and response words. For the cued-recall test, the subjects were given a page containing a random ordering of the 40 stimulus words from the two lists and were asked to write for $5 \mathrm{~min}$, the response words. For the recognition test, the subjects were given a page with 80 word pairs and were allowed $5 \mathrm{~min}$ to circle the word from each pair that came from the previous lists.

Materials. The 160 common one-syllable four- and five-letter English nouns were selected from the Kŭcera and Francis (1967) word frequency norms. These were divided randomly into 80 words for Set $\mathrm{X}$ and 80 for Set $\mathrm{Y}$. Each set was again divided into two parts, 40 words for List 1 and 40 for List 2. Each list was then divided into two parts: 20 words were stimuli and 20 were responses for the 20 pairs in each list.

The immediate cued-recall tests for Lists 1 and 2 for both Sets $\mathrm{X}$ and $\mathrm{Y}$ were made by typing a column of the 20 stimulus words in their original order.

The final cued-recall test was a randomized mix of the 40 stimulus words from both Lists 1 and 2 combined.

The recognition test contained 80 word pairs. Each pair contained one Set $\mathrm{X}$ word and one Set $\mathrm{Y}$ word. Set $\mathrm{X}$ words served as distractors when Set $Y$ words were targets, and vice versa. The 80 words from each set were ordered randomly.

Environmental contexts. Room A was a $6 \times 6 \mathrm{ft}$ experimental cubicle with bare walls, a table, and two chairs. Room B was a larger laboratory with a one-way mirror on one wall, cabinets and shelves, and seating for 15 subjects.

\section{Results and Discussion}

Separate $2 \times 2 \times 2$ (test room $\times$ GEFT $\times$ word set) ANOVAs were computed for free-recall, cued-recall, and recognition test conditions, using each subject's context score (i.e., number correct on SC list - number correct on DC list) as a dependent measure.

As can be seen in Table 2, the test context influenced memory performance on all three types of memory test, indicated by the fact that all context scores were greater than zero. Not all effects, however, were significant.

On the recognition test, the context scores were greater than zero $[\mathrm{t}(72)=2.15, \mathrm{p}<.05]$, indicating that $\mathrm{SC}$ lists were recognized better than DC lists. This finding of context-dependent recognition memory is consistent with the results of Experiment 1; in both cases, the recognition test consisted of words from multiple input lists, and in both the critical comparisons were (SC vs. DC) within subjects.

The analysis of the recognition results also found a significant effect of test room $[F(1,72)=19.07$, MSe = $10.28, \mathrm{p}<.001$ ], indicating a larger effect for subjects tested in their second input context. This does not mean that the second input room induced greater CDM. Rather,
Table 2

Experiment 2: Mean Numbers Correct* and Context Scores as a Function of Test Type and Cognitive Style

\begin{tabular}{lrrr} 
& \multicolumn{2}{c}{ Cognitive Style } & \\
\cline { 2 - 3 } Test Type & $\begin{array}{c}\text { Field } \\
\text { Dependent }\end{array}$ & $\begin{array}{c}\text { Field } \\
\text { Independent }\end{array}$ & $\begin{array}{c}\text { All } \\
\text { Subjects }\end{array}$ \\
\hline Free Recall & & & \\
SC List & 11.73 & 14.20 & 12.97 \\
DC List & 11.38 & 13.62 & 12.50 \\
Context Score (SC - DC) & .35 & .58 & .47 \\
Cued Recall & & & \\
SC List & 8.00 & 10.35 & 9.18 \\
DC List & 7.33 & 10.05 & 8.69 \\
Context Score (SC - DC) & .67 & .30 & .49 \\
Recognition & & & \\
SC List & 34.95 & 35.48 & 35.22 \\
DC List & 33.75 & 35.08 & 34.42 \\
Context Score (SC - DC) & 1.20 & .40 & .80 \\
\hline
\end{tabular}

*For free recall and recognition, there were 40 possible, and for cued recall there were 20 possible.

it indicates a recency effect; the list presented second (i.e., the SC list when testing occurred in the second room, and the DC list when testing was in the first room) was recognized better than the list presented first.

The analysis of cued-recall context scores indicated that although SC lists were remembered better than DC lists (see Table 2), the mean of the context scores was not significantly different from zero $[\mathrm{t}(72)=1.16, \mathrm{p}>.05]$. As in the recognition results, there was a significant effect of test room $[\mathrm{F}(1,72)=41.44, \mathrm{MSe}=14.78, \mathrm{p}<$ .001 ], again indicating a recency effect.

The analysis of the free-recall condition, like the cuedrecall results, indicated that although SC lists were recalled better than DC lists (see Table 2), the mean of the context scores was not significantly different from zero $[t(72)=.80, p>.05]$. As with the recognition and cuedrecall conditions, the effect of test room (the recency effect) was significant $[F(1,72)=125.35$, MSe $=23.19$, $\mathrm{p}<.001]$. The failure to find CDM on the free-recall test is particularly surprising in light of the finding that recognition memory was significantly affected by the identical learning conditions and context manipulations.

One possible explanation of the failure to observe ECdependent free recall is that most subjects recalled words from List 2 before recalling List 1 words, regardless of test conditions. Output interference (Rundus, 1973) could have biased subjects to recall List 2 words, thus overshadowing the effects of contextual recall cues.

Results concerning the field dependence/independence factor (GEFT) were inconclusive. As shown in Table 2, field-dependent subjects overall showed more CDM than field-independent subjects. The GEFT factor, however, had no significant effects for any test type. Nonetheless, one statistic, output order of the two lists, was affected by this personality measure. The number of fieldindependent subjects beginning output with List 1 was nearly the same in both test rooms, whereas fielddependent subjects were more likely to recall List 1 first 
when tested in Room A (the room in which List 1 was studied) than when tested in Room B. A $2 \times 2$ (GEFT $\times$ test room) $\chi^{2}$ indicated the reliability of this interaction $\left[\chi^{2}(1)=7.22, \mathrm{p}<.05\right]$.

\section{GENERAL DISCUSSION}

EC-dependent recognition memory was found both in Experiment 1 and Experiment 2 . The effects were small, but statistically significant. In Experiment 2, for example, the mean difference between SC and DC lists constituted a $2 \%$ difference in mean overall performance, as contrasted with differences of $10 \%-25 \%$ in CDM studies that used free-recall tests (e.g., Smith, 1979). The greatly reduced error variance associated with the present within-subjects EC manipulation appears to have been essential for detecting such small effects.

It should be noted that the dichotomy between anecdotal experiences and laboratory evidence is reduced by the present study. Recognition in everyday experiences, especially recognition of a person, is commonly reported to fail if the person is viewed in a new or unusual context; yet laboratory studies have heretofore failed to find effects of environmental manipulations on recognition. Rather than denying the existence of EC-dependent recognition memory, it may be more worthwhile to search for those circumstances in which EC-dependent recognition does occur, and to look for ways to capture and study the phenomenon in the laboratory.

\section{REFERENCES}

Bartlett, J. C., \& Santrock, J. W. (1979). Affect-dependent episodic memory in young children. Child Development, 50, 513-518.

CraIG, A. (1979). Nonparametric measures of sensory efficiency for sustained monitoring tasks. Human Factors, 21, 69-78.

EICH, J. E. (1980). The cue-dependent nature of state-dependent retrieval. Memory \& Cognition, 8, 157-173.

GodDEN, D. R., \& BADDELEY, A. D. (1975). Context-dependent memory in two natural environments: On land and underwater. British Journal of Psychology, 66, 325-331.

GoDDEN, D. R., \& BADDELEY, A. D. (1980). When does context influence recognition memory? British Journal of Psychology, 71, 99-104.

JACOBY, L. L. (1983). Perceptual enhancement: Persistent effects of an experience. Journal of Experimental Psychology: Human Learning, Memory, and Cognition, 9, 21-38.

KǔCERA, H., \& FrANCIS, W. N. (1967). Computational analysis of present-day American English. Providence, RI: Brown University Press.

Oltman, P. K., Raskin, E., \& WitKin, H. A. (1971). Group Embedded Figures Test. Palo Alto, CA: Consulting Psychologists Press. Rundus, D. (1973). Negative effects of using list items as recall cues. Journal of Verbal Learning and Verbal Behaviors, 12, 43-50.

SMith, S. M. (1979). Remembering in and out of context. Journal of Experimental Psychology: Human Learning and Memory, 5, 460-471.

Sмiтн, S. M. (1983). Cognitive style and context-dependent memory. Presented at the meeting of the Midwestern Psychological Association, Minneapolis, $\mathrm{MN}$

Smith, S. M., Glenberg, A. M., \& BJork, R. A. (1978). Environmental context and human memory. Memory \& Cognition, 6, 342-353.

Sмiтн, S. M., \& RothкоPF, E. Z. (1984). Contextual enrichment and distribution of practice in the classroom. Cognition and Instruction, 1, 341-358.

SPEAR, N. E. (1978). The processing of memories: Forgetting and retention. Hillsdale, NJ: Erlbaum.

\section{NOTE}

1. The $A^{\prime}$ measure, a nonparametric analog to $d^{\prime}$ (Craig, 1979), was computed as follows: (1) If hit rate $(H)$ exceeded false-alarm rate $(F)$, then $\mathrm{A}^{\prime}=.5+[(\mathrm{H}-\mathrm{F})(1+\mathrm{H}-\mathrm{F})] /[4 \mathrm{H}(1-\mathrm{F})] ;(2)$ if $\mathrm{H}$ was less than $F$, then $A^{\prime}=.5-[(F-H)(1+F-H)] /[4 F(1-H)]$. The maximum value of $\mathrm{A}^{\prime}$ is 1.0 , and chance performance is .5 .

(Manuscript received for publication December 13, 1985.) 